\title{
O sentimento urbano em Vastas emoções e pensamentos imperfeitos
}

\author{
Seleste Michels da Rosa*
}

\begin{abstract}
Resumo: Este ensaio pretende analisar a constituição do indivíduo moldado pelo espaço urbano, conforme a discussão sobre o ser na modernidade iniciada por Benjamin, no romance Vastas emoções e pensamentos imperfeitos de Rubem Fonseca; levando em conta aspectos comuns ao homem moderno como a solidão, a forma inovadora de ver a religião, a sua maneira peculiar de manter um relacionamento amoroso e a sua atitude ao lidar com os diversos tipos de cultura que o mundo da cidade oferece.
\end{abstract}

\begin{abstract}
This essay intends to analyze the formation of the individual shaped by the urban space in the novel Vastas emoções e pensamentos imperfeitos by Rubem Fonseca, according to the discussion about the modern human being started by Benjamin. The aspects taken into account were the ones commonly shared by the modern men, such as loneliness, the innovative way to see religion, their peculiar way of keeping a love relationship and their attitude when dealing with different kinds of culture which are offered by the city world.
\end{abstract}

Keywords: city; identity; habits; feelings

Palavras-Chave: Cidade; Identidade; Hábitos; Sentimentos

Toda a narrativa de Rubem Fonseca é caracterizada pela identificação com a temática da cidade, principalmente com o amoral e o violento. O personagem construído em Vastas emoções e pensamentos imperfeitos corresponde tão completamente a essa idéia que parecenos exemplar, pois vai se degradando ao longo da narrativa, ou seja, diante dos olhos do leitor, e se aproximando cada vez de uma moral marginalizada até atingi-la por completo. Além disso, as inquietações, os conflitos e o meio em que o personagem está inserido estão intimamente ligados a esse espaço. Por isso, analisaremos o romance através da ótica da formação urbana, tanto sentimental quanto culturalmente.

O protagonista-narrador inicia seu relato no Rio de Janeiro, vai à Europa e volta ao Brasil, no Rio é seqüestrado, e ao fugir do cativeiro, passa por cidades do interior de Minas, por fim retorna a sua cidade de origem. O protagonista que nos leva a esse passeio está em estado de total estagnação no ponto inicial da narrativa. Ele está à parte da sociedade capitalista, pois está desempregado e não desempenha nenhum papel produtivo. A

\footnotetext{
* Mestranda UFRGS.
} 
personalidade deste homem foi gerada dentro dos valores e parâmetros da cidade, ele vive nela desde criança, contudo o contato com o suburbano acontece no momento de abertura da narrativa quando uma desconhecida bate a porta portando diamantes. A partir desse momento a decadência moral do personagem começa a se evidenciar. São estes problemas que queremos analisar: a identidade do ser conformado pela cidade, seus valores morais e sua forma de lidar com as relações interpessoais, com os sentimentos, com as culpas e os traumas.

O protagonista é um homem urbano, suas mais remotas memórias de infância são de uma loja que o pai possuía. "No fim tinha um pequeno armarinho - sempre tivera lojas que fossem freqüentadas por mulheres - na rua Senhor dos Passos" (FONSECA, 1988, p.12). Logo, seu pai sempre teve uma profissão urbana, diretamente atrelada ao pequeno comércio, típico da cidade. Destarte nosso protagonista é um ser criado na cidade, numa metrópole, pois ao que parece nunca morou fora do Rio de Janeiro. Sua cidade se modificou, não tem mais os quintais com carambolas, mas continua com seus traços urbanos e ele é totalmente pertencente àquele meio. Fica muito evidente no texto que a relação do personagem com a cidade é de perfeita integração. Segundo Park (1973, p.26), "A cidade é para o homem civilizado o que a casa é para o camponês". Isso fica patente no cotidiano do protagonista, sua alimentação se dá primordialmente na rua, são mencionadas sete refeições, todas preparadas em restaurantes. Ele nunca cozinha em sua casa, o que o desvincula daquela residência de interior onde a cozinha é o centro da vida social (na sociedade brasileira); sua cozinha é na rua, ele come principalmente em restaurantes, a única vez que não o faz, ele pede comida pela tele-entrega. Assim a cidade entra em completa conexão com seu espaço de vivência.

Segundo Berman (2006, p.352), o comportamento de total integração com as inovações modernas é um comportamento comum, "homens e mulheres modernos não pretendem resistir à modernidade". O personagem de Fonseca está completamente adaptado ao meio moderno e às invenções da modernidade. Por isso, as inquietações que o acometem também são totalmente provenientes desse mundo. Até mesmo a doença que possui é ligada à forma da cidade: a Síndrome de Menière, ou seja, uma doença que ataca o labirinto fazendo com que a pessoa perca a noção de espaço e tempo. Aquele é uma metáfora da cidade, ou seja, até a enfermidade está, de certa maneira, relacionada ao espaço físico. A construção das urbes, na maioria das vezes, não segue modelos cartesianos de organização, ela parece se estabelecer aleatoriamente a partir de um simples aglomerado de moradias, algumas vezes ao redor de uma praça e de uma igreja, que, partindo desse centro, forma diversos caminhos sinuosos e de difícil compreensão para quem não domina aquele local. Por isso, a possibilidade de se perder é grande, e é justamente essa a sensação reproduzida pela moléstia. 
Uma das maiores inquietações do personagem-protagonista é própria do homem moderno, pois este, segundo Simmel, tem dificuldade de expressar seus sentimentos, que são sufocados na solidão. O personagem tem consciência de seu isolamento, de que não compartilha seus sentimentos com ninguém, por isso entra num processo de recalque e negação, preferindo não os revelar nem a si mesmo. O narrador não quer falar sobre Ruth, ele afirma isso treze vezes ao longo do texto, marcando isso sempre que vê alguma coisa que lembre dela ou quando Liliana propõe o assunto, mostrando assim a mágoa e a culpa a respeito daquilo sobre o que se nega a falar. Ele só consegue atenuar sua culpa quando, finalmente, relata todo o episódio do acidente de Ruth.

A solidão em que ele vive é conseqüência da modernidade, que retira os indivíduos da sociedade rural, onde são reconhecidos como pessoas, donas de uma história e, por conseguinte, de uma significação, e os põe em um lugar onde todos são iguais, e logo onde não são reconhecidos como pessoas, seres especiais ligados a um significado e a um sentimento que possibilita o relacionamento. Isso faz com que o homem moderno seja, sobretudo, um ser solitário. Ele não vê ninguém como seu par, todos são percebidos como superiores ou inferiores e essa hierarquia impossibilita uma relação profunda com a troca de informações pessoais e sentimentais. Isso acontece entre o protagonista e todos os personagens. Podemos começar exemplificando com José. Seu irmão é visto como muito inferior culturalmente, mas muito superior em termos de sucesso na sociedade burguesa. Sua amante, Liliana é muito jovem e tem interesses diferentes, além de já ter ultrapassado sua sapiência, pois era bastante inocente quando o conheceu e hoje sabe mais do que ele, o que o incomoda. Angélica e os outros personagens envolvidos com o carnaval são muito inferiores economicamente. Enfim, o protagonista não tem um único amigo, um igual. Boris é o único com quem partilha interesses, mas ele está mais para mestre do que para amigo, o que impossibilita a confissão.

Desta forma se constrói um indivíduo com uma baixa auto-estima o que é apontado pelo fato de o personagem não ter nome. Em nenhum momento é mencionado seu nome, nem por terceiros, nem em alguma elucubração sua, isso o torna sem identidade, é alguém que não se sente especial por nada, simplesmente percebe-se como mera peça do maquinário urbano, mais um no meio de muitos. Isso também decorre da falta de religiosidade, ele não se sente como um ser criado por Deus, especial, com algum objetivo nobre a cumprir, ele é só mais um destes animais que nascem e morrem sem motivo transcendente. A única vez que atribui um nome próprio a si mesmo, está usando um nome falso, o nome do cartão de crédito que roubou para fugir. Assim ele encarna a falsidade que todos os outros objetos envolvidos na 
trama apontam, o manuscrito falso e os diamantes verdadeiros encobertos entre os falsos. Desta forma, todos os valores ficam escondidos na incerteza da veracidade, tanto os valores morais quanto os valores materiais.

Os demais personagens têm nome, isso é indicativo de que ele se sente diferente frente à identidade dos demais, visto que é ele quem narra esse relato, além disso, ele passa todo o tempo se menosprezando. Vê seu irmão como alguém que consegue obter mais sucesso que ele apesar do pouco estudo, sente inveja por isso; seu irmão lhe parece mais habilidoso do que ele desde menino.

Ódio por ele? Sim, eu o detestava, desde pequeno, desde quando ele caçava moscas e arrancava-lhes as asas e depois colocava-as no chão e dizia "quero ver você voar agora, mosca." Mas eu não o odiava por arrancar as asas da mosca, eu o odiava por sua fantástica habilidade em pegar as moscas. (...) Devia saber que uma pessoa com aquela inventividade e impiedade teria um futuro brilhante, e morria de inveja por isso. (FONSECA, 2004. p.37)

Esse sentimento se mantém mesmo quando os dois estão adultos (José fala para ele "Você precisa controlar o seu rancor" (FONSECA, 2004, p.218)); pois José continua sendo mais feliz em seus intentos, tem reconhecimento, dinheiro, casa, carro e família. Além disso, vê em Liliana uma jovem a quem ele ensinou muitas coisas e hoje já sabe muito mais coisas que ele, afinal ele não tem uma memória tão boa. Percebe Veronika como muito mais inteligente e bem informada que ele. ("Você não gostou de Veronika?" [...] "Ela sabe coisas demais. Até para um alemão isto não é bom" (FONSECA, 2004, p.131)). Também vê o talento e a possibilidade de crescimento de Ruth ("Uma bailarina com grande futuro" (FONSECA, 2004, p.221-222)); mas não vê um futuro para si, está há dois anos sem filmar e desconfia da proposta de Plessner, pois não considera seu filme tão bom assim. Por sentir-se agredido pela identidade do outro, sempre mais poderosa, ele prefere ficar só.

O habitante da metrópole moderna, incessantemente submetido a "vivências de choque", impactos que ele tem de aparar aguçando ao máximo sua consciência, vive por reflexos e não tem tempo para formar sua experiência, um eidos de vida, uma imagem de si. (BOLLE, 1994, p.345)

Assim é o homem moderno, precisa passar cada vez mais tempo sozinho a fim de se tornar tão sapiente e especializado que seja insubstituível. Nosso protagonista passa muito tempo estudando, trabalhando e assistindo filmes a fim de ficar cada vez melhor em sua técnica, mas isso o leva a um isolamento paulatinamente maior. Ele tem mais informações, mas menos experiência, pois ele não tem tempo de deixar as informações e os acontecimentos amadurecerem, por isso, ele simplesmente reage às situações em que se vê envolvido e não reflete, não percebe as mudanças que essas vivências lhe trazem.

Ele está tão isolado que isso se mostra mesmo em relação a si próprio, ele se estranha, não reconhece sua imagem, ao se ver no espelho confunde suas feições com as de seu pai 
quando velho, mas ele era quarenta anos mais novo que seu pai quando este tinha aquele semblante.

[...] eu não olhava sujeito algum numa mesa próxima: olhava-me, a mim mesmo, refletido. Era eu, aquela pessoa macilenta que parecia meu pai. Meu coração ficou gelado. Meu pai ao morrer tinha quarenta anos mais do que eu! Era então minha aquela cara velha devastada? (FONSECA, 2004, p.12)

A solidão e a falta de alguém com quem conversar fazem com que a culpa fique sempre latente, sem a possibilidade de ser purgada. Portanto, ela o assola justamente por ele não ter para quem confessar. Uma das razões para isso acontecer é uma consequiência da modernidade que substituiu a divindade pela ciência, pois nosso personagem não está ligado a nenhuma religião que o redima. "O homem moderno não precisava de Deus, precisava de uma ética, de amor, de tolerância... Que merda, eu estava inventando uma religião nova, inventando a roda" (FONSECA, 2004, p.38).

Desta maneira, ele não acredita na confissão e expiação de seus pecados, que é como ele caracteriza a morte de Ruth, então, os recalca e sofre. Segundo Hillman, a psicanálise é uma ciência moderna; por isso o sujeito moderno não tem um Deus a quem recorrer para que este alivie sua culpa, então ele a carrega enquanto pode, até que não seja mais possível e isso se expresse numa autoconfissão, na racionalização destes sentimentos, numa sessão de análise, ou ainda de uma forma violenta. Segundo Rolim, um dos fatores causadores da violência urbana é a falta de tradição e cultura religiosa que está imbricada nela. Tendo em vista que essas pessoas não temem um castigo posterior e não tem uma moral tão sedimentada, elas liberam seus instintos, justamente o que a civilização tenta apagar.

Quando o protagonista recebe Angélica, ela diz para ele uma frase que expressa a problemática do mundo moderno. "Muito obrigada por ter salvo a minha vida. Neste mundo cruel e egoísta de hoje é uma surpresa encontrar um homem tão generoso como você." (FONSECA, 2004, p.10). Mas ele não é generoso, nem mesmo ele sabe porque a deixou entrar e passar a noite, ele é só mais um ser isolado na cidade. Com Angélica nasce a possibilidade de uma comunicação, pois só com uma mulher tão rebaixada ele poderia falar de sua dor, ele não teria vergonha de se mostrar frágil.

\footnotetext{
"Você está triste?", perguntou.

"Estou." Para aquela mulher monstruosa eu não tinha vergonha de confessar que estava triste.

Normalmente os homens não ficam tristes. Pelo menos os que conheço. Por que sua casa está tão bagunçada? Meu Deus! Parece que passou um tufão por aqui."

Logo que acabou de dizer isso começou a dormir, sem me dar tempo de responder. (FONSECA, 2004, p.10)
}

Angélica esboça a aproximação, mas dorme, desmancha-se desta maneira qualquer comunicação que pudesse haver. Esta personagem, que parece ser só o fator desencadeante do 
problema da narrativa, é muito importante por ser, em todo livro, apesar do pouco ou nenhum relacionamento que estabeleceu com o narrador, a única possibilidade de comunicação, de expiação da culpa. Ao amanhecer, ela vai embora antes que o protagonista acorde e é assassinada ainda nesse dia; sendo assim, o protagonista perde a única pessoa para quem teria coragem de contar o que acontecera, por isso, ele não revela sua dor a ninguém, e só confessa a si mesmo bastante tempo depois, num momento de crise total. Sua grande angústia está relacionada à perda de sua esposa Ruth, uma bailarina a quem admirava.

Agora eu queria pensar em Ruth novamente. E era bom que estivesse com aquele capuz na cabeça, pois assim não poderiam presenciar minha dor.

Sempre que lembrava do acidente, eu dizia para mim mesmo que não tivera culpa. Uma bailarina com grande futuro que fica paralítica num estúpido desastre de automóvel parece filme lacrimoso feito para a sessão da tarde da tv. Mas aconteceu. E eu não tive culpa. (FONSECA, 2004, p.221-222)

Desta forma, apesar de conseguir falar a respeito do que aconteceu a Ruth, parece que sua preocupação maior é mostrar que não teve culpa, isso revela o quanto ele sente remorso por ter sido, de certa forma, responsável pelo que aconteceu a Ruth. Afinal, ele não tem uma religião que o redima, não há um Deus a quem possa pedir perdão e aliviar essa dor, ele também não recorre à terapia. Entretanto, fala quando a violência urbana o atinge frontalmente, quando foi seqüestrado e está trancado no porta-malas de um carro com um capuz cobrindo sua cabeça, por isso a violência que sofre também age como um detonador que aciona seu trauma.

Apesar de sua solidão, o tempo em que o narrador interage com outros personagens é dominado pelas mulheres, salvo a relação com Boris, e, de certa maneira, ele está subjugado a elas. Benjamim já fala sobre a maior participação da mulher na cidade moderna e da beleza das figuras lésbicas. "A lésbica é a heroína da modernidade. Fio condutor da eroticidade em Baudelaire - essa mulher fala da dureza e da masculinidade -, ela foi penetrada por um temário histórico: o da grandeza no mundo antigo" (KOTHE, Flávio, 1991, p.113).

Ruth e Liliana eram companheiras quando ele as conheceu, ele casou com Ruth, mas acabou se envolvendo com Liliana, principalmente depois do acidente que, por impedir o movimento das pernas, dificultou a vida sexual de Ruth. Nesse relacionamento, ele simplesmente se deixa levar por elas e não aparenta nenhuma reação a essa dominação. Isso pode ser visto principalmente com Liliana que é a relação mais explorada no texto, ela o seduz e o convence de fazer sempre o que propõe. Contudo a mulher exaltada por Benjamin e apresentada na obra não é mulher feminina que mostre os aspectos maternais e domésticos, ela é a mulher masculinizada, forte, agressiva. No texto, esse aspecto é incorporado por 
Liliana e tem um contraponto na mãe do protagonista, uma mulher forte, mas totalmente dedicada à família.

O certo é que sempre tivera uma relação complicada com as mulheres a minha volta, quer tivesse com elas um envolvimento sentimental - como ocorria com Liliana, como havia ocorrido com Ruth - quer a relação fosse profissional, quer fosse familiar. Pensei na minha mãe. Ela era uma mulher dominadora, dedicada à família, para ela só existia o pai, eu e o meu irmão. Mas havíamos pago um alto preço por essa dedicação, eu mais do que todos. (FONSECA, 2004, p.134)

A violência é mais vinculada à masculinidade, segundo Rolim (2006, p.263), "violência que é, historicamente, uma marca masculina, em todas as civilizações". Por isso, essa característica deve ser ressaltada até mesmo na mulher, segundo Benjamin, na cidade não tem lugar para o carinho, o afeto, a maternidade; ela é um espaço de total egoísmo e, portanto, de agressividade. Contudo, ainda se mantém a distinção entre os sexos na maneira de ver a violência, esta é marcada em dois momentos: em uma conversa entre o narrador e Liliana e depois numa conversa daquele com Veronika.

"Por que você está gritando para mim essas coisas, de olho arregalado. O que foi? Pirou?", disse Liliana.

"É um trecho do meu filme."

"O camaradinha passa a ser respeitado pelos seus pares porque matou um ganso? É este o significado da cena?", perguntou Liliana. "Ah! Vocês meninos!" (FONSECA, 2004, p.97)

Apesar de quase todo seu contato com outras pessoas se dar através de mulheres, ele afirma não ter afinidade com elas, isso mostra sua dificuldade de interação com o mundo. Esse aspecto também é reforçado na área sexual, onde ele sempre quer dar prazer ao invés de querer ter prazer também, revelando uma espécie de falta de envolvimento com o sexo oposto. Ele é subjugado por elas nas situações cotidianas, então quer mudar de posto, quer tomar o poder da relação, pelo menos na sexual. Ele não se propõe a troca, mas a uma exibição de capacidades, ele compete com as mulheres mesmo na cama. Todavia, essa falta de envolvimento expõe o quanto os impulsos sexuais não o comovem mais. Ele tem a seu lado uma mulher que acha linda e não tem desejo real por ela, não quer saciar seu desejo e sim o dela para fazer com que ela o valorize e assim ele tenha uma distinção, deixe de ser substituível.

Deitei-a na cama. A luz de seu corpo era a do nascer do sol. Tenho que saciá-la, pensei, fazê-la gozar repetidas vezes, usar minha capacidade de ficar com o pênis ereto por um tempo infindável sem gozar, meu prazer é secundário. A velha dúvida me assaltou - generosidade ou exibicionismo? - apenas por alguns instantes. (FONSECA, 2004, p.152)

A falta de envolvimento cria a dúvida entre generosidade ou exibicionismo, ou seja, a dúvida revela a total falta de envolvimento; apesar de o estímulo ser grande, afinal o próprio protagonista se manifesta interessado na beleza desta mulher, assim ele mostra-se um tanto anestesiado frente ao prazer que esta parceira pode oferecer, ele não se entusiasma com isso, 
permanece completamente racional. Esse comportamento comprova que o narrador já teve inúmeras parceiras, e todas as que os leitores conheceram eram lindas, essa exposição continuada ao estímulo sexual é o que o faz se tornar quase indiferente, desvendando um comportamento blasé, segundo Simmel.

Uma vida em perseguição desregrada ao prazer torna uma pessoa blasé porque agita os nervos até seu ponto de mais forte reatividade por um tempo tão longo que eles finalmente cessam de reagir. [...] Surge assim a incapacidade de reagir a novas situações com a energia apropriada. (SIMMEL, 1973, p.16)

Por isso, ao encontrar Veronika, uma mulher linda, e ir com ela para a cama, ele não quer aproveitar a situação, ele quer fazer com ela sinta mais prazer e assim ele se reafirma perante si próprio, mas só é capaz de usar o sexo dessa forma por não estar tão sensível a ele quanto seria esperado, por isso pode suprimir seu desejo e se auto-afirmar como macho capaz de dar todo o prazer que as mulheres necessitam.

O protagonista tem outra característica típica da psique urbana que é a hiperracionalização, ele tem um sentimento reprimido com relação à Ruth do qual foge ao longo de todo texto, escondendo-se no envolvimento com Bábel. Quando finalmente ele aceita pensar no que aconteceu à Ruth, ele racionaliza o fato tentando se sentir livre da culpa de estar dirigindo o carro no acidente que a levou a ficar paraplégica e por consequiência se matar. "Ruth estava cochilando, Ruth pediu-me que dirigisse o carro. Qual a minha culpa? Antes eu não pensava no acidente nestes termos. Minha racionalização ainda me levaria a culpar Ruth pelo que aconteceu" (FONSECA, 2004, p.222).

A vida agitada, o extremo cansaço, o violento trânsito urbano, enfim a cidade é quem tem a verdadeira responsabilidade pela perda de mais essa vida; mas o personagem não é capaz de refletir sobre a sua vivência, ele não ultrapassa os limites do acidente, por isso nunca se vê livre da culpa. Ainda assim, usa toda sua capacidade de racionalização a fim de não se sentir culpado. Isso, além de ser uma maneira moderna de livra-se da culpa também é, segundo Simmel, uma característica do modo de vida urbano.

A vida metropolitana, assim, implica uma consciência elevada e uma predominância da inteligência no homem metropolitano. A reação aos fenômenos metropolitanos é transferida àquele órgão menos sensível e bastante afastado da zona mais profunda da personalidade. A intelectualidade, assim, se destina a preservar a vida subjetiva contra o poder avassalador da vida metropolitana. (SIMMEL, 1973, p.13)

É com essa intelectualidade que o protagonista-narrador fala da relação de seu irmão com a religiosidade. José é um homem competente e tem uma relação com o dinheiro bem melhor que a sua; sempre foi bem sucedido em todas as atividades comerciais em que se envolveu. "José sabia vender. Deixara de estudar, ainda menino, para vender coisas. Fora 
camelô, vendendo bugigangas contrabandeadas, depois vendera enciclopédias de porta em porta, depois carros usados, agora vendia a salvação das almas" (FONSECA, 2004, p.17).

Já o protagonista vê toda a fé como um comércio; isso torna o isolamento ainda maior, pois o impossibilita de comunicar-se com seu irmão e o põe num mundo sem Deus. Essa também é uma característica da sociedade moderna: a ausência de fé, segundo Rolim. Esse traço de personalidade é bastante acentuado através do contraste com o pastor. Ele vê a crença desse com uma bobagem ou uma mentira a qual ele prega só para ganhar dinheiro e respeitabilidade, por todo texto ele tenta mostrar como o outro é falso, mas por fim admite que aquele tem verdadeiramente fé no que prega.

Um vigarista se faz passar por homem de bem, assume o código de honra deste e acaba sacrificando, por isso, a própria vida. Seria meu irmão um velhaco como esse personagem vivido por De Sica, que se redime afinal por acreditar na própria mentira? Olhei bem para o seu rosto. (FONSECA, 2004, p.217)

A sociedade tradicional é geralmente é ligada a um rito religioso e essa ligação faz com a sociedade esteja totalmente definida para o sujeito; as questões de ética estão divididas em certos e errados e não há lugar para controvérsias, todos os lugares sociais estão ocupados e são fixos ${ }^{1}$. Isso falta a nosso protagonista, ele não tem padrões éticos definidos, sua ética vai se modificando conforme seus interesses, já que somente ele se condenará ou absolverá, tendo em vista que ele é um "tribunal soberano", logo procura as justificativas mais apropriadas para suas atitudes. Assim como toda a sociedade a seu redor, o cineasta alemão que queria contrabandear o manuscrito, os traficantes de diamante, enfim o mundo que o rodeia, até mesmo Liliana que a princípio não quer aceitar o dinheiro proveniente das pedras contrabandeadas, mas acaba fazendo. Há um momento em que a própria racionalização leva o personagem a se justificar por uma ação imoral.

“(...) Estou pensando em vender as pedras de Angélica Maldonado. Já te disse que ela não tem família. Minha ação pode ser criminosa, do ponto de vista legal, mas não é moralmente condenável. Ou você acha que o Alcobaça é o legítimo proprietário delas"

"Você está racionalizando." (FONSECA, 2004. p.84)

Rolim (2006) afirma que na sociedade tradicional, intimamente atrelada à religião, os valores morais eram rígidos e obrigatórios, por serem dogmas. Todavia essa estrutura não se mantém na sociedade moderna. Hoje a religião é uma opção, o que faz com que os valores sejam próprios de cada indivíduo. Um dos fatores que permite a degradação do personagem é sua falta de fé, sem ela não se vê forçado a julgar seus atos de forma negativa. Ele não acredita no transcendente, nem na punição das almas, por isso a moral é só sua, ele é um

1 Cf. ROLIM, Marcos. Violência e modernidade. In: SCHÜLER, Fernando, AXT, Gunter. Brasil Contemporâneo: crônicas de um país incógnito. Porto Alegre: Artes e Ofícios, 2006. 
tribunal interno. Segundo Rolim (2006, p.257), “o indivíduo moderno é, ele mesmo, um tribunal soberano". Por isso nosso protagonista pode e vai se adaptando e justificando a cada vez que age em dissonância a seus próprios valores, e, como estes são só seus, a cada situação apresentada eles podem ser modificados. Não que haja uma relação direta entre a falta de fé e a decadência do personagem; todavia indiretamente há, já que a fé impõe valores morais fixos que impedem essa 'flexibilidade' moral, ainda segundo a perspectiva de Rolim. Um ser sem fé também pode ter valores morais fixos, mas não é o caso do personagem, que, como mostramos, adapta seus padrões de certo e errado cada vez que isso possa beneficiá-lo. Isso acontece no uso dos diamantes e no furto do manuscrito de forma muito clara. Nestes momentos o personagem se convence de não estar incorrendo em erro. Só não consegue fazer isso em relação ao acidente com sua esposa.

As implicações psicológicas do ambiente urbano estão ligadas ao ser moderno de forma geral, contudo algumas características culturais são específicas de cada urbe. $\mathrm{O}$ personagem, ao passar por diversas cidades, nos mostra suas culturas específicas. Na Primeira parte: A linfa do labirinto, o personagem começa sua trajetória no Rio, onde está pesquisando sobre um escritor soviético, especificamente sobre um texto que fala sobre a guerra. $\mathrm{Na}$ segunda parte, $O$ manuscrito, o protagonista vai para Munique, Berlim Ocidental e Oriental e Paris. Por fim, em $O$ diamante Fiorentino, o protagonista retorna ao Rio, é seqüestrado e depois de fugir do cativeiro passa um tempo em Diamantina e volta ao Rio para concluir a trama.

Desta maneira, o texto nos faz um percurso que fala de muitas cidades, é claro que há muitas semelhanças entre as grandes cidades e estas são mostradas, mas esse texto também nos apresenta um pouco do que é peculiar a cada uma delas. Conforme Park, "a cidade é o habitat natural do homem civilizado. Por essa razão, ela é uma área cultural caracterizada por seu próprio tipo peculiar" (PARK, 1973, p.27). Então nosso protagonista é um tipo peculiar que está intimamente ligado a uma organização urbano específica, que é o Rio de Janeiro. Conforme Berman, a metrópole dos países subdesenvolvidos é diferente da européia, por sua configuração tardia que emerge do atraso e do próprio subdesenvolvimento.

O modernismo do subdesenvolvimento é forçado a se constituir de fantasias e sonhos de modernidade [...]. Contudo, a bizarra realidade de onde nasce esse modernismo e as pressões insuportáveis sob as quais se move e vive - pressões sociais e políticas, bem como espirituais infundem-lhe uma incandescência desesperada que o modernismo ocidental, tão mais a vontade nesse mundo, jamais conseguirá igualar. (BERMAN, 2006, p.260)

Sendo assim, a primeira cidade descrita tem essa conformação específica de uma metrópole do terceiro mundo. Ela sofre estas pressões e é vítima desta desorganização 
institucional sobre a qual o terceiro mundo se constrói. Nela é possível encontrar um proprietário de joalheria enredado com o contrabando de diamantes, policiais que não investigam suficientemente os casos de homicídio e tráfico fazendo com que a única repreensão temida seja a do mundo do crime onde o protagonista se vê paulatinamente mais submerso. Mas, além disso, vemos no texto as marcas culturais de cada cidade, o Rio de Janeiro mostra duas faces. A face da elite intelectual, que tem acesso praticamente ilimitado, ao conhecimento universal, representada pelo protagonista. E a face da população média que é representada pelos carnavalescos cariocas, cuja influência muda todo o andamento da cidade durante os dias de carnaval. "O trânsito estava muito atravancado, devido ao carnaval, e demorei a chegar à casa de Negromonte” (FONSECA, 2004, p.68). Os personagens envolvidos com os desfiles de carnaval têm uma formação cultural específica que é mostrada através das pesquisas feitas para a criação da fantasia. Negromonte afirma: "Eu estudei tanto para fazer aquela fantasia!... Porque eu pesquiso, sabe, nos livros, nas enciclopédias, converso com especialistas, com os sábios [...]” (FONSECA, 2004, p. 41).

Enfim, o narrador considera essa mistura de culturas, essa multiplicidade moral e cultural convivendo juntas como a linfa do labirinto que é a cidade, ou seja, aquilo que circula, que faz a vida, enfim o que promove a verdadeira vitalidade urbana. $O$ personagem está totalmente tomado por essa vertigem urbana, tanto que sua doença, a pseudo-síndrome de Menière, é caracterizada pela vertigem causada pelo desequilíbrio da linfa no labirinto auricular. Sendo assim, o protagonista é um ser completamente urbano e por isso ele se identifica com esse caldo de culturas que é o Rio, essa linfa pulsante, podendo transitar com normalidade em meio aos carnavalescos populares ou entre cineastas internacionais.

Outra característica que deve ser levada em conta é a violência do Rio de Janeiro em contraponto a outros tipos de violência e a segurança urbana de outros centros. Muitas vezes a violência da guerra descrita por Bábel é comparada à violência urbana vivida no Rio de Janeiro.

\footnotetext{
"Você vai fazer na Alemanha um filme sobre uma guerrinha que aconteceu na Europa há mais de sessenta anos? Bábel era um escritorzinho fraco, afrancesado. Faz um filme sobre a guerra que está acontecendo aqui, no teu país, agora. Esta nossa guerra hobbesiana de todos contra todos..." (FONSECA, 2004, p.32)
}

Isso levanta a questão a outro nível além da violência urbana, ela vai ao nível da própria organização capitalista e do egoísmo em geral onde cada um só pensa em defender seu patrimônio. Esse aspecto é salientado por Bolle no capítulo Em busca de uma identidade de si, onde fala da relação da criança urbana com as trancas e a segurança circundante. A criança começa a se perceber presa dentro daquela gaiola de proteção e vê que aquilo não 
acontece com todos, por isso, normalmente se revolta contra os pais e não se sente mais a vontade com aquela situação.

O contraste entre a insegurança, que era a vida no Rio de Janeiro, e a segurança, da vida na Europa, pode ser visto no episódio em que o protagonista quer ir embora do apartamento de uma de suas amantes, mas não quer deixar a moça exposta, por isso, quer deixar a porta trancada. "Para ir embora, todavia, era preciso resolver um problema. Eu viera de uma cidade violenta, onde as portas deviam sempre ser bem fechadas" (FONSECA, 2004, p.150). Essa passagem retoma a memória de infância de crianças da classe média conforme relatado em Bolle (1994). Berlim começa a mostrar suas diferenças, ela funciona de forma diversa do Rio de Janeiro quanto à violência urbana.

A cultura é outro diferencial. Em Berlim, Veronika quer levar o protagonista aos museus. Isso mostra que ela acredita que o mais significativo para o povo alemão está neste espaço, mas o protagonista se nega a participar do passeio. Então eles acabam indo ao balé, outro elemento da cultura européia, não que o balé seja apreciado somente na Europa, tanto que a esposa do protagonista era bailarina. Logo, o narrador mostra sua adaptabilidade, por ter vindo de uma metrópole jovem ele tem trânsito entre a cultura clássica e a inovadora, sua exmulher, inclusive, já tinha dançado a mesma peça. A literatura também faz esse papel de mediador entre culturas. Há um grupo constituído por um brasileiro e dois alemães, mas eles pretendem fazer um filme baseado em uma obra soviética. Isso mostra que não há hierarquia entre as culturas, mas uma interpenetração quase completa neste nível social; o próprio cinema é índice disso, também mostrado como marca cultural de Paris e Berlim, onde todos os cinemas exibem filmes dublados.

As cidades européias são descritas numa parte do livro chamada $O$ manuscrito; isso seria definidor de seu papel frente à cidade labiríntica descrita em A linfa do labirinto. As cidades do velho mundo são caracterizadas por uma alta circulação de pessoas do mundo todo, contudo, sua cultura perdeu a ligação com o popular, a parte mais criativa da sociedade, portanto está estagnada, tanto que são repetidas as peças por anos a fio, não há mais criação; são cidades-museus; por isso o protagonista se nega a ficar visitando museus, ele rejeita o passado cristalizado, não recriado.

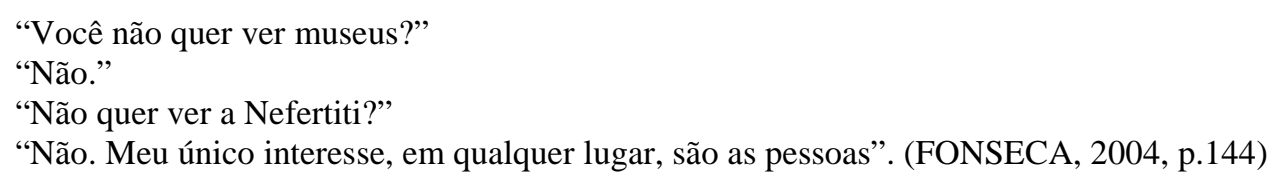

O protagonista mostra que quer ver a cultura viva, em movimento. Por isso, vai ao museu de cinema, lá ainda há inovação, mas nos convencionais só há arcaísmos. Essas 
cidades serviram de manuscrito, rascunho arcaico para as verdadeiras cidades onde a cultura se move livremente e cria condições para o contato com o diferente, esse contato é o que faz a riqueza cultural do mundo urbano e isso não ocorre mais na Europa, pois sua cultura é aquela passadista, segundo o narrador.

Por fim é mostrada a pequena cidade do interior, onde a comida é farta, todos criam laços de confiança muito rapidamente e o único traço cultural exposto é o gosto por concursos de beleza. Estes têm como função principal levar as belas jovens da região para o reconhecimento que só os grandes centros urbanos podem dar. A cidade pequena é descrita no último capítulo, chamado $O$ diamante Fiorentino, como um diamante de alta pureza. Então, ela seria o símbolo da verdadeira pureza, onde o ser humano se mostra de maneira mais natural e as relações são intensas e duradouras, contudo não é lugar de nosso protagonista, ele foge de lá deixando mentiras de que voltará.

A mulher que ele conhece, Dália, se afeiçoa a ele e confia nele logo no primeiro olhar, também o dono do hotel o protege do inquérito do delegado, por uma simples simpatia, enquanto ele, homem urbano, está pensando em enganá-los e roubá-los; sem ao menos sentirse culpado, pois sua moral flexível permite que ele aja desta maneira. Sendo assim, apesar deste mundo ser melhor, nosso protagonista não está adaptado a ele, por isso, ele volta ao Rio.

$\mathrm{O}$ texto explora todas as maneiras de um ser humano, apesar de completamente adaptado à vida urbana, reagir aos constantes estímulos que a cidade lhe proporciona e às limitações psicológicas que essa condição o obriga. Mostrando assim o modus vivendi de um ser urbano em seu habitat natural. Revela ainda as diferenças que podem haver, dentro de tantas semelhanças entre as diversas cidades onde o protagonista transitou, desvendando por fim onde é seu verdadeiro lugar no mundo: a linfa do labirinto, onde continua sendo anônimo e mantendo contato com a cultura viva e movimentada do 'novo mundo'.

\section{Referências}

BERMAN, Marshall. Tudo que é sólido desmancha no ar: a aventura da modernidade. São Paulo: Companhia das Letras, 2006.

BOLLE, Willi. Fisiognomia da metrópole moderna. São Paulo: Edusp, 1994.

FONSECA, Rubem. Vastas emoções e sentimentos imperfeitos. São Paulo: Companhia das Letras, 2004.

HILLMAN, James. Cidade \& Alma. São Paulo: Studio Nobel, 1993. 
KOTHE, Flávio (org). Walter Benjamin: sociologia. São Paulo: Ática, 1991.

PALLAMIN, Vera. Cidade e Cultura: esfera pública e transformação urbana. São Paulo: Estação Liberdade, 2002.

PARK, Robert Ezra. A cidade: Sugestões para a investigação do comportamento humano no meio urbano. In: VELHO, Otávio Guilherme. O fenômeno urbano. Rio de Janeiro: Zahar, 1973.

ROLIM, Marcos. Violência e Modernidade. In: SCHÜLER, Fernando, AXT, Gunter. Brasil Contemporâneo: crônicas de um país incógnito. Porto Alegre: Artes e Ofícios, 2006.

SCHÜLER, Fernando, AXT, Gunter. Brasil Contemporâneo: crônicas de um país incógnito. Porto Alegre: Artes e Ofícios, 2006.

SIMMEL, Georg. A metrópole e a vida mental. In: VELHO, Otávio. O fenômeno urbano. Rio de Janeiro: Zahar, 1973.

VELHO, Otávio Guilherme. O fenômeno urbano. Rio de Janeiro: Zahar, 1973. 